\title{
Differences in the Performance of Female and Male Students: A Case Study of Second Language Learning
}

\author{
Jianyang Huang ${ }^{1, *}$ \\ ${ }^{1}$ The Raymond J. Harbert College of Business, Auburn University, Auburn, Alabama, United States
${ }^{*}$ Corresponding author. Email: jzh0180@auburn.edu.
}

\begin{abstract}
With language learning and teaching approaches, gender differences have started to gain attention in recent years. Rapid changes in the education industry need the evaluation system to keep updating for testing students' knowledge. In light of academic achievement is the direct presentation of the quality of education, and the performance of students demonstrated their levels of acquiring knowledge, skills, and proficiencies. Thus, it is crucial for a notion to develop its students' academic achievements, as students' academic performance can reflect the current and the future of a nation. Therefore, understanding gender's role is of practical and theoretical significance in language testing. Therefore, to investigate the academic performance of students of different genders, this paper will focus on one area, namely their attitudes towards second language learning and testing. Reviewing students' views of second language learning can provide important students feedback to assist a better understanding of the second language teaching from the students' perspective.
\end{abstract}

Keywords: gender differences, Chinese students, second language learning

\section{INTRODUCTION}

The body text starts with a standard first-level heading like INTRODUCTION or any other heading suitable to the content and context. First level headings are in all caps. Copy the content and replace it for other first-level headings in rem

In language learning, researchers usually pay more attention to very "big" fields like motivation while few researchers would like to focus on "small" sides like genders. Nowadays, with the development of gender power, researchers started to consider gender differences as a necessary variable influencing the results. Especially when talking about language learning strategies and language learning assessment. Considering external and internal factors plays a crucial role in affecting students' academic performance [10]. Previous studies found that academic performance was related to students' emotional intelligence, motivation, anxiety, depression, stress [13], test takers' general world knowledge, educational and socioeconomic status background, and age [1]. However, the function of those factors is further considered refers to gender differences, which means the effectiveness of factors may differ regarding the specific gender type.
The issue of gender differences has been discussed in the whole world for a long time. Gender differences are proved to exist in pay gap [3], education [2], and politics [9]. In the past 25 years, the proportion of women involved in higher education has been sharply increased, while the trend in participation of women in education still shown significant gender differences [7], which may cause biased viewpoints on students in learning for both gender types. As a result, the form of gender differences presented in education was disputed. Some researchers supported that men performed better than women with a higher proportion of first-class degrees, and some assessment methods are inequality for women [7]. While others may argue that there are no significant differences in both males and females in their study if both genders come from the same country [14]. Therefore, it is necessary to examine gender differences in the language learning process and provide more useful information for defining the gender differences in students' performance with the improvement of educational equality.

However, the academic performance in different subjects may be varied, which may cause biased data collected; the setting of participants in this project needs to be narrowed. Therefore, to investigate students' academic performance, this article will focus on one 
domain: their attitude towards second language learning and testing.

With the general aims of the whole project, this research is going to answer the following questions:

1. What factors affect male and female students' language performance most?

2. To what extent can gender causes differences in learning language?

Meanwhile, the focus of investigation participants involved in this research will be Chinese students who present to have acquired English as a second foreign language. Therefore, it is pivotal to investigate Chinese male and female students' performance on language learning and testing in general and on the personal attitudes towards academic life in specific, as well as to discuss and analyze the effect of gender, especially the influence of gender differences on language learning.

Although emotional intelligence, test anxiety and academic stress were proven to be influential to students' performance, among them, gender differences were also pointed, or even factors mentioned ahead should be further analysed cross-gender. Although discussing gender differences in academic performance can provide valuable feedback to assist a better understanding of academic quality from the students' perspective, understanding the particular differences of each gender is practical and theoretical. Thus, this article mainly focuses on the relations between gender differences and second language learning, along with investigating test takers' attitudes towards learning, can largely help teachers make language learning more effective that it provided implications for the learning, teaching and testing of language learning from the perspective of test users [10].

\section{LITERATURE REVIEW}

\subsection{Introduction}

This part aims to introduce and analyze the existing literature on the factors that affected students' performance and gender differences existed situations. Seven articles or reports are involved in this part, and they are classified into three sections, which indicate the meaning topic of each material. However, two articles related to students' performance are the main resources for this paper, as they are mentioned repeatedly in the following content. The first focus of this part is a gender difference in performance because it is significant having a rough idea about the position of the effect of gender. And then, the performance in language learning and testing of students is discussed further in detail. After that, the particular situation of gender differences in China is mentioned, since the intended participants of this research are Chinese, which need to consider the ethics and cultural difference.

\subsection{Factors Influence Language Learning}

Oxford (1994), in her study, mentioned several factors including motivation, gender, cultural background, attitude and beliefs, type of task, age and second language (L2) stage, learning style and tolerance of ambiguity, which have an impact on the choice of L2 learning strategies.

Generally speaking, highly motivated students would behave better in language learning. Besides, many people believe that females would make better choices of learning strategies than males, and this concern will be discussed in this paper. In addition, students growing in different cultural backgrounds may have a preference for different strategies. Also, ages, attitudes and beliefs are the other internal factors that influence learners' behaviors. Type of task and tolerance of ambiguity are external factors that work on the learners as well. And learning style, which is usually combined with the teaching style, should be considered too.

\subsection{Gender differences in performance}

In recent years, it is evident that the participation of women in higher education was sharply increased, especially women accounted for $40 \%$ by 1990 and to just under one-half by 1999 , while the gender differences were found to be an affected factor in degree performance [7]. Moreover, researchers found that women are mostly less possibly to gain a first-class degree, which illustrates the need to prove the determinants of gender differences in an academic environment, as varied factors affect the performance of students [7]. Thus, this report was limited in its application, as little evidence can be drawn from the finding that gender differences in performance can reflect an individual's academic ability.

According to Stankovska, Dimitrovski and Angelkoska's results, emotional intelligence can be the most influential factor of students' academic achievement. At the same time, the finding presented that female college students overperformed male students (Stankovska, Dimitrovski and Angelkoska). However, a question that needs to be asked is whether the academic achievement of those students shows significantly different concerning emotional intelligence across gender. This called attention to the other statement that in the test anxiety, the gender differences did not perform as a critical factor to affect their performance, but the major students chosen may be influential [13]. On the other hand, researchers found that females were more stressed than males; they were affected more by academic stress because women often 
examined themselves following the ideal image. Besides, girls were more sensitive to feelings, while boys were more capable of dealing with impulses and tolerating stress, which caused their performance as well. Meanwhile, researchers in the other project stated that students' satisfaction with college life can significantly influence their performance, such as males in this study appeared to score lower than females [4].

\subsection{Gender differences in language learning}

The gender differences were also demonstrated in many aspects, which was further proven that ways of learning of females and males were different, caused the performance differently, particularly on language learning. The outcome of learning was also shown in second language learning [10] that the gender differences performance based on the ESL classroom, focused on the language learning setting. This article correctly argued that the way men and women in language use are significantly different from men appears to overperform women in communication and promote their productive skills.

However, Abdo Rahimzadeh found that no matter participants in ESL or EFL settings, gender differences in reading interests and preferences did not demonstrate reading comprehension proficiency, which is critical as it was strong evidence to question the way gender differences affect students' academic performance. While this research was limited by the sample design, students' literacy was different due to the setting of age being from 15 years old to 20 years old, which could be significantly different across the evident literacy gap. It may have been more illustrative if the research narrowed the setting of target participants.

\subsection{Gender differences in China}

Apart from that, male prejudice or bias was introduced [7]. On the basis of this statement, selfesteem and life satisfaction cross-gender were prosed, especially considering the context of China at current and in the past [14]. In the view of $\mathrm{Ye}, \mathrm{Yu}$ and $\mathrm{Li}$, they believed current students from only one child family might perform differently from the past that traditional Chinese parents may pay more attention to boys' education. However, as the rapid changes of the society in China, the differential gender differences across cultures should be considered [15].

Besides, the gender gap was also prevailed according to the performance-based pay differences [3].herefore, the study suggested that the gender differences, which supported that gender inequality existed in an academic environment. However, the setting of the participant of this study was different from the intended target of the following research, as participants involved in this report were the staff.
Nevertheless, in general, this literature is useful for knowing the academic circumstance of universities in China.

\subsection{Summary}

In conclusion, gender differences in performance can be demonstrated from the perception of test anxiety, emotional intelligence, self-esteem, and life satisfaction. The differences in language learning and testing also exist that females and males present differences across gender. Moreover, considering the context difference, the situation of China, and nowadays Chinese students should be considered for further analysis. The present knowledge is mostly based on a large number of participants. However, the target participants were not classified in detail. Therefore, in this project, the group of participants will be narrowed to Chinese students. The target subject that needs to be used as the comparison standard will be their performance in language learning and testing to investigate further the gender differences in students' performance in particular areas.

\section{DISCUSSION}

In light of the data [6], 500 Chinese participants have provided useful information for this project to investigate the research questions "What factor affect male and female students' language performance most?" and "To what extent can gender causes differences in learning a language?" Based on the equivalent number of female and male students and similar conceptual knowledge they perceived, the answer for the first question should be "motivation", as their motivation presents priority highly in their perception of second language learning. Besides, topic interest has been proven, causing the differences across gender [1], which research sources can prove.

It is critical to clear the relation between the first question and the second question to answer the second question. It is factors function that gender differences may happen; however, more situations should be taken into consideration. There are no significant differences across genders when responses related to participants' attitudes towards language learning. While only the interest-oriented issues presented obvious differences. Thus, gender differences did not function in students' performance. However, in specific, males and females have different orientations towards second language learning, which may cause differences in academic performance. Besides, males take more advantage than females of opportunities to communicate in second language learning, as they are more willing to practice, which Shehadeh mentioned as well [10].

On the whole, the research questions were appropriately answered. However, particular significant 
limitations need to be stressed in this study, and more researches are needed, such as questionnaires and interviews data. First, the participants in this study are not firsthand data, and there are certain differences in time. Although data collected is authentic, limited statistics may still have validity and reliability, such as the grade of Chinese students should be more specific as different grades may have diverse performance in the learning process. Second, the research assumed participants obtained similar knowledge backgrounds. However, students have individual differences. Even most of them may regard themselves as possessed average level language performance. Therefore, the actual proficiency may not meet the standard. Thus, further research should take a language assessment to examine students' actual proficiency. Based on that, a qualitative research method can also be conducted to investigate participants' perception in specific towards second language learning and testing across genders. Last but not least, this research did not consider personal gender cognition, while this should be a critical factor in analyzing gender differences.

\section{CONCLUSION}

In conclusion, this study focuses on investigating the influence of gender differences on language learning, which reflects the different performances of females and males. After a brief introduction of the whole research, the literature review was presented to introduce and analyze the existing literature on the factors that affected Chinese students' performance, and gender differences existed situations. Following that, the analysis as the most pivotal part of this study was performed in the discussion section. Though the length is limited, the answer to the research questions was further discussed. Due to the limitation of this study, future researches should take reliable data collection, actual performance assessment, and gender cognition into consideration. However, this article can generally be a useful reference for reviewing the performance differences, especially second language learning differences across genders.

\section{REFERENCES}

[1] Abdorahimzadeh, Seyedjamal. "Gender differences and EFL reading comprehension: revisiting topic interest and test performance." System (2014): 7080 .

[2] Bayeh, Endalcachew. "The role of empowering women and achieving gender equality to the sustainable development of Ethiopia." Pacific Science Review B: Humanities and Social Sciences (2016): 37-42.

[3] Guo, Qian, et al. "Gender differences in performance-based pay: evidence from a Chinese university." China Economic Review (2016): $104-$ 113.

[4] Jorgensen, Shirley, Catherine Fichten and Alice Havel. "College Satisfaction and Academic Success." Final Report Presented to PAREA. 2011.

[5] Kayaoglu, M. Naci. "Gender-based differences in language learning strategies of science students." Journal of Turkish Science Education (2012): 1224.

[6] Kissau, Scott. "Gender Differences in Second Language Motivation: An Investigation of Microand Macro- level influences." Canadian Journal of Applied Linguistics, (2012): 73-96.

[7] Mcnabb, Robert, Sarmistha Pal and Peter Sloane. "Gender Differences in ducational attainment: the case of university students in England and Wales." Economica (2002): 481-503.

[8] Oxford, R. Language Learning Strategies: An Update. 1997. 23092021.

[9] Pascall, Gillian and Jane Lewis. "Emerging gender regimes and policies for gender equality in a wider Europe." Jnl Soc. Pol. (2004): 373-394.

[10] Shehadeh, Ali. "Gender differences and equal opportunities in the ESL classroom." ELT Journal (1999): 256-261.

[11]"Emotional Intelligence, Test Anxiety and Academic Stress among University Students." ERIC Clearinghouse (2018): 157-164.

[12] Sunderland, Jane. "Gender in the EFL classroom." ELT Journal (1992): 81-91.

[13] Stankovska, G., Dimitrovski, D., ngelkoska, S., Ibraimi, Z., \& Uka, V. (2017, November 30). Emotional intelligence, test anxiety and academic stress among university students. Bulgarian Comparative Education Society. Retrieved October 10, 2021, from https://eric.ed.gov/?id=ED586176. Page 157-164

[14] Viriya, Chayata and Sutthirak Sapsirin. "Gender differences in language learning style and language learning strategies." Idonesian Journal of Applied Linguistics (2014): 77-88.

[15] Ye, Shengquan, Lu Yu and Kin-Kit Li. "A crosslagged model of self-esteem and life satisfaction: gender differences among Chinese university students." Personality and Individual Differences (2012): 546-551. 